\title{
CORPO LEGAL: O QUE DIZEM OS DOCUMENTOS DA EDUCAÇÃO BÁSICA SOBRE O CORPO?
}

\author{
LEGAL BODY: WHAT DO BASIC EDUCATION DOCUMENTS SAY ABOUT THE BODY?
}

\author{
EL CUERPO JURÍDICO: ¿QUÉ DICEN LOS DOCUMENTOS SOBRE LA EDUCACIÓN \\ BÁSICA SOBRE EL CUERPO?
}

\author{
Andrea Pereira Martins Vinhas 1 \\ Cilene Margarete Pereira ${ }^{2}$
}

\begin{abstract}
Resumo
Este artigo apresenta como o conceito de corpo vem sendo tratado em documentos que regulamentam a Educação Básica no país, entre eles a Lei de Diretrizes e Bases da Educação (LDB/1996), os Parâmetros Curriculares Nacionais (PCNs/1997), as Diretrizes Curriculares Nacionais para a Educação Básica (DCNs/2013) e a Base Nacional Comum Curricular (BNCC/2017), dando especial destaque ao modo como a Educação Física, referente ao Ensino Fundamental, apreende a noção de corpo. Os documentos citados normatizam e direcionam as ações realizadas no âmbito escolar, servindo como ponto de partida obrigatório para a construção de currículos e de materiais educacionais e educativos para uso na educação formal ou informal. A análise dos documentos mostra uma elaboração do conceito de corpo, abandonando uma visão apenas técnica e fisio-biológica para se pensar também em cultura, historicidade e diversidade corporal.
\end{abstract}

Palavras-chave: Corpo, Documentos educacionais, Educação Básica, Educação Física.

\begin{abstract}
This study presents how the body concept has been being treated in documents that regulate Basic Education in the country, among them the Lei de Diretrizes e Bases da Educação (LDB/1996), the Parâmetros Curriculares Nacionais (PCNs/1997), the Diretrizes Curriculares Nacionais para a Educação Básica (DCNs/2013) and the Base Nacional Comum Curricular (BNCC/2017), with special emphasis on how Physical Education, during Junior Schooling, apprehends the body notion. The abovementioned documents normalize and direct the actions performed at school ambience, serving as mandatory starting point for the construction of background as well as educative and educational materials to be used with formal or informal education. The analysis of the documents shows an elaboration of the body concept, abandoning a view that was essentially technical, physiological and biological to turn the attention to culture, historicity and body diversity as well.
\end{abstract}

Key words: Body, Educational documents, Basic Education, Physical Education.

\section{Resumen}

En este artículo se presenta cómo el concepto de cuerpo és tratado en documentos que regulan la Educación Basica en el país, entre ellos la Lei de Diretrizes e Bases da Educação (LDB/1996), los Parâmetros Curriculares Nacionais (PCNs/1997), las Diretrizes Curriculares Nacionais para a Educação Básica (DCNs/2013) y la Base Nacional Comum Curricular (BNCC/2017), con énfasis especial en el modo en que la Educación Física, referida a la Educaión Primaria, aprehende la noción de cuerpo. Los documentos mencionados normalizan y orientan las acciones echas en la escuela, y serven como punto de partida obrigatorio para la construcción de planes de estudios y de materiales educativos para uso en la educación formal o informal. El análisis de los documentos muestra una elaboración del concepto de cuerpo, abandonando así uma mirada

\footnotetext{
1 Mestranda em Gestão, Planejamento e Ensino; educadora física. E-mail: prof.andrea.vinhas@unincor.edu.br

2 Doutora em Teoria e História Literária pela UNICAMP; autora de A assunção do papel social em Machado de Assis: uma leitura do Memorial de Aires (2007), editado pela Annablume em parceria com a FAPESP, de Jogos e Cenas do Casamento (2011), editado pelas Appris e Prismas. E-mail: cilene.margarete.pereira@gmail.com
} 
solamente técnica, fisiológica y biológica para pensar también en la cultura, la historididad y la diversidad corporal.

Palabras clave: Cuerpo, Documentos educativos, Educación Básica, Educación Física.

\section{CONSIDERAÇÕES INICIAIS}

$\mathrm{Na}$ Educação Básica frequentemente comparece um discurso que se refere à formação integral do aluno, pensada a partir de princípios éticos, políticos e estéticos, conforme disposto nas Diretrizes Curriculares Nacionais para a Educação Básica (DCNs) de 2013. 0 último documento educacional a fazer referência a essa formação integral é a Base Nacional Comum Curricular (BNCC), que teve, em 2017, sua versão aprovada para o ensino fundamental. ${ }^{3}$

Na definição das dez competências gerais da Educação Básica, a BNCC reconhece que a educação deve ser amparada por valores e ações éticas com o objetivo de construir uma sociedade mais justa e humana, reafirmado a importância da educação em direitos humanos (BRASIL, 2017, p. 6), compreendida por um conjunto de atividades educativas com o fim de promover a capacitação e o acesso a informações "orientadas para criar uma cultura universal de direitos humanos" (UNESCO, 2006, p. 1).

Entre as dez competências gerais apresentadas na BNCC, as 8, 9 e 10 dizem respeito aos direitos humanos, pois evidenciam o reconhecimento da diversidade de indivíduos e grupos sociais, o exercício da empatia e o respeito ao outro como valor ético e humano e estimulam ações individuais ou coletivas que estejam comprometidas com a inclusão e a solidariedade. (BRASIL, 2017, p. 8).

Ainda que, em um primeiro momento, a competência 8 possa se vincular de modo direto à Educação Física, pois trata da saúde física e emocional do sujeito, ${ }^{4}$ as três competências citadas perpassam o componente curricular, na medida em que apontam temáticas referentes também às relações entre indivíduos e grupos sociais e dialogam com questões de corpo, estigma, adolescência e como a percepção da imagem corporal atua nessa uma fase de transição da vida do aluno.

Considerando o contexto acima, este artigo apresenta como o conceito de corpo vem sendo tratado em documentos que regulamentam a Educação Básica no país, entre eles a Lei de Diretrizes e Bases da Educação (LDB/1996), os Parâmetros Curriculares Nacionais (PCNs/1997), as Diretrizes Curriculares Nacionais para a Educação Básica (DCNs/2013) e a

\footnotetext{
${ }^{3}$ Neste artigo, por tratarmos do Ensino Fundamental, iremos usar a versão aprovada em 2017, visto que não houve mudanças relativas a esse segmento no documento final de 2018, no qual consta o Ensino Médio.

${ }^{4}$ Diz a competência 8: "Conhecer-se, apreciar-se e cuidar de sua saúde física e emocional, compreendendo-se na diversidade humana e reconhecendo suas emoç̃es e as dos outros, com autocrítica e capacidade para lidar com elas." (BRASIL, 2017, p. 7)
}

Revista de Ciências Humanas, Frederico Westphalen - RS, v. 22, n.2, p. 132-151, maio/ago. 2021.

Recebido em: 27/02/2021 $\quad$ Aceito em: 21/06/2021


Base Nacional Comum Curricular (BNCC/2017), dando especial destaque ao modo como a Educação Física, referente ao Ensino Fundamental, apreende a noção de corpo. Os documentos citados normatizam e direcionam as ações realizadas no âmbito escolar, servindo como ponto de partida obrigatório para a construção de currículos e de materiais educacionais e educativos para uso na Educação formal ou informal.

\title{
CORPO LEGAL
}

Documentos que regem a Educação Básica no Brasil tratam de forma pouco especifica ou simplesmente ignoram a dimensão corporal, apesar de este aspecto ser tão importante e significativo na formação do ser humano. Apesar do discurso referente à formação integral do aluno e de algumas observações sobre a importância do corpo e do movimento em relação a este desenvolvimento, a demonstração de forma efetiva ainda é pouco considerada nos documentos oficiais.

Para Ana Maria Preve e Guilherme Corrêa, o corpo é tratado no ambiente escolar a partir de movimentos como docilização, por meio do confinamento na carteira e do controle disciplinar, e de sua forma, sendo reduzido a estruturas anatômicas e fisiológicas, dotado, portanto, de uma estatização:

\begin{abstract}
É um corpo que, sem nome, sem cara, sem desejo, sem subjetividade, é transformado em objeto de estudo. Estudar o corpo, na escola, significa apropriar-se do conteúdo de suas partes e funções, para que depois, ou seja, fora da escola, o aluno consiga aplicar este conhecimento em prol da sua qualidade de vida politicamente correta. $\mathrm{O}$ corpo que a escola nos faz ver é um corpo didático, rígido, como que um subproduto de aulas de anatomia. (PREVE; CORRÊA, 2000, s/p)
\end{abstract}

A Lei de Diretrizes e Bases da Educação (LDB), de 1971, não se referia ao termo corpo de forma específica, mas à Educação Física como área que trata o corpo de modo tecnicista e militarista, com ênfase na dimensão biológica. Marcus Aurélio de Oliveira observa que a Educação Física escolar foi formatada de maneira autoritária, com direcionamentos impostos pelo Estado, e as reformas na Educação foram regidas com base nas leis 5.540/1968 e 5.692/1071 e o decreto 69.450/1971: "Dentro dessa perspectiva os intelectuais a serviço do governo teriam gestado as políticas públicas para a educação no período aqui abordado. Para a Educação Física escolar a Lei 5.692/71 reserva, em seu artigo $7^{\circ}$, um espaço de obrigatoriedade nos currículos escolares." (OLIVEIRA, 2002, p. 53).

Os Parâmetros Curriculares Nacionais (PCNs) da Educação Física, de 1997, em sua contextualização histórica, pontuam o papel e a forma como a Educação Física foi conduzida: "Nesse quadro, em 1968, com a Lei n. 5.540, e, em 1971, com a 5.692, a Educação Física teve 
seu caráter instrumental reforçado: era considerada uma atividade prática, voltada para 0 desempenho técnico e físico do aluno." (BRASIL, 1997, p. 20) Como ferramenta desta proposta, o esporte se configurava como conteúdo referência, visto que "As práticas escolares de educação física passaram a ter como fundamento primeiro a técnica esportiva, o gesto técnico, a repetição, enfim, a redução das possibilidades corporais a algumas poucas técnicas estereotipadas." (OLIVEIRA, 2002, p. 53). Oliveira observa que essa perspectiva coloca que

[...] o esporte codificado, normatizado e institucionalizado pode responder de forma bastante significativa aos anseios de controle por parte do poder, uma vez que tende a padronizar a ação dos agentes educacionais, tanto do professor quanto do aluno; noutra, porque o esporte se afirmava como fenômeno cultural de massa contemporâneo e universal, afirmando-se, portanto, como possibilidade educacional privilegiada. (OLIVEIRA, 2002, p. 53)

A educação brasileira passou por diversas transformações e mudanças nas décadas de 1980 e 90, tendo como marco a promulgação da nova LDB, sancionada em 20 de dezembro de 1996, sob o $n^{0}$. 9.394/96. Diversas mudanças foram propostas pelo novo documento, para uma adequação da Educação e dos seus processos. Guiomar de Mello aponta que

\begin{abstract}
Com a promulgação da Lei no 9.394/96, a nova Lei de Diretrizes e Bases da Educação Nacional (LDB), que incorporou as experiências e lições aprendidas ao longo desses anos, inicia-se outra etapa de reforma. Em relação à flexibilidade, regime de colaboração recíproca entre os entes da federação e autonomia dos entes escolares, a nova LDB consolidou e tornou norma uma profunda ressignificação do processo de ensinar e aprender: prescreveu um paradigma curricular no qual os conteúdos de ensino deixam de ter importância em si mesmos e são entendidos como meios para produzir aprendizagem e constituir competências nos alunos. (MELLO, 2000 p. 98)
\end{abstract}

Em seu artigo $4^{\circ}$, o texto estabelece que a Educação Básica é composta pela Educação Infantil, Ensino Fundamental e Ensino Médio. (Cf. BRASIL, 1996, p. 8). A novidade aí estava na incorporação do Ensino Médio, considerado etapa final do processo educativo básico a ser ofertado pelo Estado. Em relação à nova estrutura da Educação Básica, o artigo 26 da LDB/1996 estabelece que:

Os currículos da educação infantil, do ensino fundamental e do ensino médio devem ter base nacional comum, a ser complementada, em cada sistema de ensino e em cada estabelecimento escolar, por uma parte diversificada, exigida pelas características regionais e locais da sociedade, da cultura, da economia e dos educandos. (BRASIL, 1996, p. 12).

Colocava-se, assim, a existência de dois currículos paralelos, um que contemplaria a formação basilar do aluno (tarefa da BNCC), outro, que atenderia às especificidades da escola, considerando seu público, interesses e questões regionais.

A Educação Física é referida no parágrafo $3^{0}$ :

Revista de Ciências Humanas, Frederico Westphalen - RS, v. 22, n.2, p. 132-151, maio/ago. 2021. Recebido em: 27/02/2021 Aceito em: 21/06/2021 
$\S 3^{\circ} \mathrm{A}$ educação física, integrada à proposta pedagógica da escola, é componente curricular obrigatório da educação básica, sendo sua prática facultativa ao aluno:

I - que cumpra jornada de trabalho igual ou superior a seis horas;

II - maior de trinta anos de idade;

III - que estiver prestando serviço militar inicial ou que, em situação similar, estiver obrigado à prática da educação física;

IV - amparado pelo Decreto-Lei no 1.044, de 21 de outubro de 1969;

V - (VETADO) (Incluído pela Lei no 10.793, de 10.12.2003)

$\mathrm{VI}$ - que tenha prole. (BRASIL, 1996, p.12)

Atualmente, além da Lei $n^{0}$ 9.394/96, que estabelece as Diretrizes e Bases da Educação Nacional, os documentos que norteiam a Educação Básica são os Parâmetros Curriculares Nacionais (PCNs), as Diretrizes Curriculares Nacionais para a Educação Básica (DCNs), de 2013, e a Base Nacional Comum Curricular, aprovada, em sua primeira versão (sem o Ensino Médio), em 2017.

Os PCNs constituíam um referencial para a educação no Ensino Fundamental em todo 0 país: "Sua função é orientar e garantir a coerência dos investimentos no sistema educacional, socializando discussões, pesquisas e recomendações, subsidiando a participação de técnicos e professores brasileiros." (BRASIL, 1997, p. 13). Em relação à Educação Física, o documento "traz uma proposta que procura democratizar, humanizar e diversificar a prática pedagógica da área, buscando ampliar, de uma visão apenas biológica, para um trabalho que incorpore as dimensões afetivas, cognitivas e socioculturais dos alunos." (BRASIL, 1997, p. 15)

Os PCNs de Educação Física são divididos em dois volumes: um referente ao primeiro e segundo ciclos e o outro, aos terceiro e quarto ciclos. 0 primeiro volume se estrutura em duas partes: (1) descreve a trajetória histórica, sua relação com a cidadania e o processo ensino aprendizagem e os objetivos para esta etapa de ensino; (2) aborda o trabalho das "séries" iniciais, apontando objetivos, conteúdos, divididos em blocos (Esportes, jogos, lutas e ginásticas/Conhecimentos sobre o corpo/Atividades rítmicas e expressivas. (Cf. BRASIL, 1997, p. 15). $O$ segundo volume "apresenta a síntese dos princípios que norteiam a Educação Física no ensino fundamental. A seguir, localiza as principais tendências pedagógicas e desenvolve a concepção da área, situando-a como produção cultural." (BRASIL, 1998, p. 15)

A Educação Física é abordada como "Cultura corporal", termo que identifica a forma dos PCNs pensarem a proposta de trabalho a partir da perspectiva do documento:

Assim, a área de Educação Física hoje contempla múltiplos conhecimentos produzidos e usufruídos pela sociedade a respeito do corpo e do movimento. Entre eles, se consideram fundamentais as atividades culturais de movimento com finalidades de lazer, expressão de sentimentos, afetos e emoções, e com 
possibilidades de promoção, recuperação e manutenção da saúde. (BRASIL, 1997, p. 23)

Em um primeiro momento, vemos que o documento elabora melhor o entendimento do corpo, pensado não só em sua dimensão biológica e tecnicista, mas também em sua relação à saúde, às emoções e às expressões do sujeito, inserido em um dado contexto socio-históricocultural. Nesse sentido, o documento aponta que "É tarefa da Educação Física escolar, portanto, garantir o acesso dos alunos às práticas da cultura corporal, contribuir para a construção de um estilo pessoal de exercê-las e oferecer instrumentos para que sejam capazes de apreciá-las criticamente." (BRASIL, 1997, p. 24)

O termo corpo vem comtemplado de forma específica como um dos blocos de conteúdo. Apesar de entender que o corpo é "um organismo integrado e não [...] um amontoado de 'partes' e 'aparelhos', mas "um corpo vivo, que interage com o meio físico e cultural, que sente dor, prazer, alegria, medo, etc." (BRASIL, 1997, p. 36), o documento volta à dimensão biológica de modo bastante enfático:

\footnotetext{
Para se conhecer o corpo abordam-se os conhecimentos anatômicos, fisiológicos, biomecânicos e bioquímicos que capacitam a análise crítica dos programas de atividade física e o estabelecimento de critérios para julgamento, escolha e realização que regulem as próprias atividades corporais saudáveis, seja no trabalho ou no lazer. (BRASIL, 1997, p. 36)
}

Uma das novidades importantes dos PCNs é a inserção de temas transversais, chamados assim por não dizerem respeito a uma disciplina ou área de conhecimento específico e por tratarem de temas contemporâneos: "Os Temas Transversais têm natureza diferente das áreas convencionais. Sua complexidade faz com que nenhuma das áreas, isoladamente, seja suficiente para abordá-los. Ao contrário, a problemática dos Temas Transversais atravessa os diferentes campos do conhecimento". (BRASIL, 1997, p. 29). Os temas transversais são "propostos na perspectiva da educação para a cidadania, como estratégia de introdução na escola das demandas atuais da sociedade, incorporando-se na sua dinâmica questões que fazem parte do cotidiano dos alunos, com as quais se confrontam diariamente" (CANDAU apud DIAS, 2017, p. 30).

Entre os seis temas transversais existentes (Ética, Pluralidade Cultural, Meio ambiente, Saúde, Orientação sexual e Trabalho e consumo), três se associam de modo direto com a questão o corpo: Pluralidade Cultural, Saúde e Orientação sexual, desdobrando-se em temas como (1) Pluralidade Cultural e a vida dos adolescentes no Brasil; (2) Autoconhecimento para o autocuidado; (3) Corpo: matriz da sexualidade. Os temas acima se associam, portanto, ao corpo adolescente, que pode ser entendido a partir de fatores como transitoriedade, mudanças de 
ordem física, que dizem respeito à constituição corporal do indivíduo e alterações psicossociais, nas quais podemos elencar a própria sexualidade.

Para a Organização Mundial da Saúde (OMS), "A adolescência é um período da vida com uma série de transformações amplas, rápidas e variadas que ocorrem entre os 10 e os 20 anos. Entre 10 e 14 anos, o menino e a menina começam a se tornar adultos, cada um com suas próprias maneiras de crescer." (OMS, 1965, p. 3). A OMS observa uma faixa etária bastante extensa, de cerca de 10 anos, compreendendo que dentro desta, no período 10 a 14 anos, mudanças particulares se dão. Esse período corresponde, no caso brasileiro, à segunda etapa do Ensino Fundamental, representado pelos 6. ${ }^{\circ}, 7 .^{\circ}, 8 .^{\circ}$ e $9 .^{\circ}$ anos.

Já o Estatuto da Criança e do Adolescente (ECA), Lei № 8.069, de 13 de julho de 1990, no seu artigo $2^{\circ}$, afirma que "Considera-se criança, para os efeitos desta Lei, a pessoa até doze anos de idade incompletos, e adolescente aquela entre doze e dezoito anos de idade." (BRASIL, 2019, p. 15). Vemos, assim, que enquanto a OMS não faz distinção entre 0 adolescente e a criança, mas aponta a fase de maiores transformações (10 a 14 anos); o ECA pontua bem seu entendimento, distinguindo, para efeitos da lei, as duas fases do processo de desenvolvimento humano. No final da adolescência se daria, portanto, com a maioridade penal.

Ao se tentar classificar a adolescência considerando a faixa etária e o desenvolvimento físico pode-se naturalizar o entendimento desta etapa da vida do ser humano. Além destes aspectos, outros também podem levar a uma percepção de que o adolescente tem desenhado 0 que ele deve ser e fazer assim que entrar na puberdade. Por isso, "Os enfoques que buscam universalizar e naturalizar a adolescência são insuficientes enquanto ferramenta de análise da complexidade dessa fase do desenvolvimento." (SOUZA; SILVA, 2019, p. 2). Marcia Melo e Gilmar Cruz afirmam que "não há como determinar que todos os indivíduos que possuem determinada idade e passam por uma dessas fases do desenvolvimento humano, sejam desta ou daquela maneira, simplesmente pelo fato de serem crianças ou adolescente." (MELO; CRUZ, 2012, s/p).

Fumika Peres e Cornélio Rosenburg também abordam a adolescência de forma dinâmica e como "fenômeno existencial", que, como tal, "afeta a cada um de nós" discordando de pressupostos que "partem da noção de que o processo adolescente é universal, e, portanto, natural, imanente ao processo de desenvolvimento humano, descaracterizando, assim, a existência humana como categoria histórico-social". (PERES; ROSENBUURG, 1998, p. 54, 55)

Peres e Rosenburg questionam os conceitos e os modelos que tratam a adolescência de forma natural e que levam a generalizações, desconsiderando, assim, as diferenças e desigualdades do adolescente concreto. Os autores colocam em questão a análise do 
adolescente a partir do paradigma biomédico: "Segundo esta tendência, a adolescência é considerada uma etapa de transição entre a infância e a idade adulta, tendo como base as transformações puberais, de caráter biológico, que, por sua vez, desencadeariam mudanças psicológicas e sociais, até atingir a maturidade." (PERES; ROSENBURG, 1998, p. 56).

Ao se considerar outras perspectivas, 0 adolescente passa a ser pensado de forma mais concreta e real. A perspectiva sócio-histórica traz 0 adolescente para sua função social como ator da sua construção histórica, como assevera Bock:

A adolescência é vista como uma construção social com repercussões na subjetividade e no desenvolvimento do homem moderno e não como um período natural do desenvolvimento. É um momento significado, interpretado e construído pelos homens. Estão associadas a ela marcas do desenvolvimento do corpo. Essas marcas constituem também a adolescência enquanto fenômeno social, mas o fato de existirem enquanto marcas do corpo não deve fazer da adolescência um fato natural. (BOCK, 2007, p. 68)

Para Mariana Caroni e Olga Bastos, as transformações corporais pelas quais passam os adolescentes têm efeitos sobre o comportamento destes e sobre o modo como veem a si e aos outros, "gerando alterações nas atitudes e nas relações sociais. Esse processo envolve a necessidade de autoafirmação, com contestação dos padrões vigentes e busca de novos modelos". (CARONI; BASTOS, 2015, p. 31)

Pelo exposto acima, podemos entender que um dos legados dos PCNs está na abordagem da cultura corporal, que trouxe à discussão aspectos relacionados às práticas corporais, que antes eram fortemente considerados a partir de aspectos tecnicistas apenas. Walter Correia trata desta questão, abordando as transformações ocorridas na Educação Física até chegar na proposta apresentada pelos PCNs, visto que conceitos que não eram evidentes ou considerados passam a ocupar os documentos referentes à Educação Física escolar:

\footnotetext{
No que concerne à Educação Física Escolar, tendo em vista o percurso efetuado desde 0 século XIX até os nossos dias, a premissa da inclusão, 0 respeito às diferenças individuais e identitárias de grupos, atenção aos tipos de conhecimento, 0 foco na premissa da aprendizagem significativa e relevante, a incorporação de múltiplos temas da cultura corporal de movimento na possibilidade de articulação transversal com aspectos relevantes da cultura, são dados inequívocos do processo evolutivo da área que dialoga com a sociedade e com o sistema educacional que, de forma patente, vem legitimando sua condição como disciplina e componente curricular. (CORREIA, 2014, p. 698)
}

Correia afirma que, apesar da influência construtivista, pode-se identificar nos textos que compõem os PCNs outras matrizes teóricas, apontando que "Não é difícil imaginar que o processo de elaboração conteve as dimensões de disputas por hegemonias e seus correspondentes expedientes de negociação conceitual e curricular." (CORREIA, 2014, p. 697). 
O pesquisador observa, ainda, que essa estrutura curricular deveria ter alcance nacional, isto é, atender a um país com dimensões continentais, com um povo que se difere de forma significativa, se forem considerados aspectos como costumes, realidades sociais, econômicas e culturais. $5^{5}$

As Diretrizes Curriculares Nacionais para a Educação Básica (DCNs), documento de 2013, são responsáveis por orientar a organização, a articulação, o desenvolvimento e a avaliação das propostas pedagógicas de todas as redes de ensino brasileiras. 0 documento tem 0 objetivo de

[...] estabelecer bases comuns nacionais para a educação infantil, o ensino fundamental e o ensino médio, bem como para as modalidades com que podem se apresentar, a partir das quais os sistemas federal, estaduais, distrital e municipais, por suas competências próprias e complementares, formularão as suas orientações assegurando a integração curricular das três etapas sequentes desse nível da escolarização, essencialmente para compor um todo orgânico. (BRASIL, 2013, p. 8)

A Educação Física teve o seu papel de coadjuvante reconhecido e as DCNs abordam esta questão, mesmo que no decorrer do seu texto ainda faltem explanações claras e específicas sobre a mudança e a valorização desse componente curricular como participante efetivo na formação integral do aluno. Diz o documento: "Na etapa da vida que corresponde ao Ensino Fundamental, o estatuto de cidadão vai se definindo gradativamente conforme 0 educando vai se assumindo a condição de um sujeito de direitos." (BRASIL, 2013 p. 37). Nesse processo, destaca, em relação à Educação Física, que

[...] assim como a dimensão emocional-afetiva foi, historicamente, tratada de modo periférico, a dimensão físico-corpórea também não tem merecido a atenção necessária. Aceita, geralmente, como atributo de um terreno específico - o da Educação Física Escolar - raramente se têm disseminadas compreensões mais abrangentes que nos permitam entender que 0 crescimento intelectual e afetivo não se realiza sem um corpo, e que, enquanto uma das dimensões do humano, tem sua concepção demarcada histórico-culturalmente. Desse modo, ao educador é imprescindível tomar o educando nas suas múltiplas dimensões - intelectual, social, física e emocional - e situá-las no âmbito do contexto sócio-cultural em que educador e educando estão inseridos. (BRASIL, 2013, p. 167)

As DCNs propõem a oferta de uma educação com qualidade social (BRASIL, 2013, p. 106) e trazem o conceito de qualidade em educação como uma construção histórica que se transforma de acordo com o contexto em que é construída:

\footnotetext{
${ }^{5}$ Entre as críticas feitas aos PCNs, Anegleyce Rodrigues indica a falta de diálogo e a participação da sociedade e dos professores da sua formulação: "Os PCN podem ser considerados um exemplo de política de desenvolvimento curricular neoliberal cujo modelo é chamado de centro-periferia, em que cabe ao professor executar propostas e políticas não desenvolvidas por ele, mas por especialistas e profissionais distantes do contexto e das dificuldades da escola". (RODRIGUES, 2016, p. 34)
}

Revista de Ciências Humanas, Frederico Westphalen - RS, v. 22, n.2, p. 132-151, maio/ago. 2021.

Recebido em: 27/02/2021 $\quad$ Aceito em: 21/06/2021


O conceito de qualidade da educação é uma construção histórica que assume diferentes significados em tempos e espaços diversos e tem a ver com os lugares de onde falam os sujeitos, os grupos sociais a que pertencem, os interesses e os valores envolvidos, os projetos de sociedade em jogo. (BRASIL, 2013, p. 106)

As DCNs observam ainda três princípios norteadores para o Ensino Fundamental: éticos, políticos e estéticos. Os princípios éticos dizem respeito a questões relacionadas ao bem estar de todos e ao combate a atitudes de preconceitos e de discriminação de qualquer natureza. Os princípios políticos tratam do reconhecimento dos direitos e deveres, desenvolvendo a consciência da cidadania e da responsabilidade social. Os princípios estéticos buscam promover a sensibilidade para as manifestações culturais, as diversas formas de expressão e com isto promover a construção da identidade plural que respeita e acolhe a diversidade. (BRASIL, 2013, p. 107).

Os princípios éticos, políticos e estéticos podem ser relacionados, no espaço escolar, quando pensamos em corpos e sexualidades diversas. Guacira Louro desnaturaliza a ideia de que vivemos o corpo da mesma forma:

[...] podemos entender que a sexualidade envolve rituais, linguagens, fantasias, representações, símbolos, convenções... Processos profundamente culturais e plurais. Nessa perspectiva, nada há de exclusivamente "natural" nesse terreno, a começar pela própria concepção de corpo, ou mesmo de natureza. Através de processos culturais, definimos o que é - ou não - natural; produzimos e transformamos a natureza e a biologia e, consequentemente, as tornamos históricas. (LOURO, 2000, p. 8)

Ampliando esta questão para além da sexualidade, Louro aponta a questão de gênero como um processo sociocultural que determina o que se espera de uma pessoa, comportamentos e atitudes, quando se fala de corpo masculino e corpo feminino:

Os corpos ganham sentido socialmente. A inscrição dos gêneros - feminino ou masculino - nos corpos é feita, sempre, no contexto de uma determinada cultura e, portanto, com as marcas dessa cultura. As possibilidades da sexualidade - das formas de expressar os desejos e prazeres - também são sempre socialmente estabelecidas e codificadas. As identidades de gênero e sexuais são, portanto, compostas e definidas por relações sociais, elas são moldadas pelas redes de poder de uma sociedade. (LOURO, 2000, p. 8)

A Educação Física, em seu campo de atuação, trabalha de forma direta e contribui com a formação do aluno em um período de grande transformação, que ocorre durante o Ensino Fundamental. Nesse sentido, as DCNs afirmam:

As crianças, quase sempre, percebem o sentido das transformações corporais e culturais, afetivo-emocionais, sociais, pelas quais passam. Tais transformações 
requerem-lhes reformulação da autoimagem, a que se associa o desenvolvimento cognitivo. Junto a isso, buscam referências para a formação de valores próprios, novas estratégias para lidar com as diferentes exigências que Ihes são impostas. (BRASIL, 2013, p. 37)

Ainda em seu texto, as DCNs fazem relações com o desenvolvimento integral do aluno como referido na LDB/1996 e no Estatuto da Criança e do Adolescente (ECA/1990), nos quais aspectos corpóreos são indicados quando se trata especificamente do "[...] desenvolvimento físico, mental, moral, espiritual e social." (BRASIL, 2013, p. 17):

\begin{abstract}
Além das finalidades da educação nacional enunciadas na Constituição Federal (artigo 205) e na LDB (artigo $2^{\circ}$ ), que têm como foco o pleno desenvolvimento da pessoa, a preparação para o exercício da cidadania e a qualificação para o trabalho, deve-se considerar integradamente o previsto no ECA (Lei $n^{\circ} 8.069 / 90$ ), o qual assegura, à criança e ao adolescente de até 18 anos, todos os direitos fundamentais inerentes à pessoa, as oportunidades oferecidas para o desenvolvimento físico, mental, moral, espiritual e social, em condições de liberdade e de dignidade. São direitos referentes à vida, à saúde, à alimentação, à educação, ao esporte, ao lazer, à profissionalização, à cultura, à dignidade, ao respeito mútuo, à liberdade, à convivência familiar e comunitária (artigos $2^{\circ}, 3^{\circ}$ e $4^{\circ}$ ). (BRASIL, 2013, p.17)
\end{abstract}

Para Rodrigues (2016, p. 34), tanto os PCNs quanto as DCNs foram construídos para serem parâmetros e diretrizes gerais, utilizados por escolas, órgãos públicos responsáveis por políticas educacionais como referência e para elaboração de livros e cartilhas. Além disso, eles se tornaram também referência para elaboração das avaliações que quantificam o desempenho escolar.

A partir de um longo processo de construção, consultas públicas, análises e depois de três versões apresentadas, em 20 de dezembro de 2017 foi homologada a Base Nacional Comum Curricular (BNCC) da Educação Infantil e do Ensino Fundamental, que traz em seu corpo documental referências diretas sobre a relação do corpo e a aprendizagem. Este é um documento que traz orientações e direcionamento das ações executadas no âmbito escolar, além de indicações e posicionamentos sobre as relações existentes entre as diversas dimensões envolvidas no processo educacional:

\footnotetext{
A Base Nacional Comum Curricular (BNCC) é um documento de caráter normativo que define o conjunto orgânico e progressivo de aprendizagens essenciais que todos os alunos devem desenvolver ao longo das etapas e modalidades da Educação Básica, de modo a que tenham assegurados seus direitos de aprendizagem e desenvolvimento, em conformidade com o que preceitua o Plano Nacional de Educação (PNE). (BRASIL, 2017, p. 7).
} 
Sua construção e elaboração passa por todo segmento da Educação Básica, do Ensino Infantil ao Médio, ${ }^{6}$ buscando um entrelaçamento entre as propostas e uma sequência que busca tornar o ensino progressivo, no qual os conteúdos, as ações e as propostas tenham relação e se organizem entre as etapas escolares.

Para além de uma formatação que atendesse apenas conteúdos curriculares, a BNCC apresenta competências que vão além das questões de base conceitual e técnica das ações escolares, visto que "Ao longo da Educação Básica, as aprendizagens essenciais definidas na BNCC devem concorrer para assegurar aos estudantes o desenvolvimento de dez competências gerais, que consubstanciam, no âmbito pedagógico, os direitos de aprendizagem e desenvolvimento." (BRASIL, 2017, p. 8)

Em seu texto, a BNCC define competências como "a mobilização de conhecimentos (conceitos e procedimentos), habilidades (práticas, cognitivas e socioemocionais), atitudes e valores para resolver demandas complexas da vida cotidiana, do pleno exercício da cidadania e do mundo do trabalho." (BRASIL, 2017, p. 8)

Entre as dez competências gerais apresentadas no documento, três têm relação com as questões de corpo, estigma e imagem corporal, assuntos que perpassam a Educação Física:

8. Conhecer-se, apreciar-se e cuidar de sua saúde física e emocional, compreendendo-se na diversidade humana e reconhecendo suas emoções e as dos outros, com autocrítica e capacidade para lidar com elas.

9. Exercitar a empatia, o diálogo, a resolução de conflitos e a cooperação, fazendose respeitar e promovendo o respeito ao outro e aos direitos humanos, com acolhimento e valorização da diversidade de indivíduos e de grupos sociais, seus saberes, identidades, culturas e potencialidades, sem preconceitos de qualquer natureza.

10. Agir pessoal e coletivamente com autonomia, responsabilidade, flexibilidade, resiliência e determinação, tomando decisões com base em princípios éticos, democráticos, inclusivos, sustentáveis e solidários. (BRASIL, 2017, p. 10)

Estas competências tratam de temáticas referentes à saúde física e emocional, às relações com os grupos sociais, gestão de conflitos, respeito à diversidade, princípios éticos, e dialogam com questões que são importantes, como corpo, estigma, adolescência e como a percepção da imagem corporal atua nessa uma fase de transição da vida do aluno.

Renato Novaes, Felipe Triani e Silvio Telles elaboraram um quadro que apresenta a estrutura geral da Educação Física na BNCC. Este quadro possibilita a visualização de como a Educação Física se organiza dentro da BNCC, apresentando suas divisões, estruturas, competências e habilidades.

6 O documento relativo ao Ensino Médio foi incorporado apenas em 2018, quando foi feita a junção de um documento único, datado de 2018.

Revista de Ciências Humanas, Frederico Westphalen - RS, v. 22, n.2, p. 132-151, maio/ago. 2021. 
QUADRO 1. Estrutura da Educação Física na BNCC do Ensino Fundamental

\begin{tabular}{|c|c|}
\hline Estrutura & Descrição \\
\hline Articulação com a BNCC & - 10 competências gerais para o Ensino Fundamental \\
\hline \multirow{3}{*}{$\begin{array}{l}\text { Elementos fundamentais comuns } \\
\text { às práticas corporais }\end{array}$} & 1) Movimento corporal \\
\hline & 2) Organização interna \\
\hline & 3) Produto cultural \\
\hline Dimensões do conhecimento & $\begin{array}{l}\text { 1) Experimentação; 2) Uso e apropriação; 3) Fruição; 4) Reflexão sobre } \\
\text { a ação; 5) Construção de valores; 6) Análise; 7) Compreensão; 8) } \\
\text { Protagonismo comunitário. }\end{array}$ \\
\hline Unidades temáticas & $\begin{array}{l}\text { 1) Brincadeiras e jogos; 2) Esportes (divididos em sete categorias: } \\
\text { marca; precisão; técnico-combinatório; rede/quadra dividida ou } \\
\text { parede de rebote; campo e taco; invasão ou territorial; combate); 3) } \\
\text { Ginásticas; 4) Danças; 5) Lutas; 6) Práticas corporais de aventura. }\end{array}$ \\
\hline Objetivos específicos & $\begin{array}{l}\text { - } 10 \text { competências específicas para Educação Física } \\
\text { - } \quad \text { Que se desdobram em } 69 \text { habilidades específicas. }\end{array}$ \\
\hline
\end{tabular}

Fonte: (NOVAES; TRIANI; TELLES, 2020, p. 76)

$\mathrm{Na}$ introdução da Educação Física como componente curricular, o documento coloca a questão da diversidade e da riqueza do trabalho corporal na área, pontuando a vastidão do "universo cultural" disposto ao/pelo aluno:

É fundamental frisar que a Educação Física oferece uma série de possibilidades para
enriquecer a experiência das crianças, jovens e adultos na Educação Básica,
permitindo o acesso a um vasto universo cultural. Esse universo compreende
saberes corporais, experiências estéticas, emotivas, lúdicas e agonistas, que se
inscrevem, mas não se restringem, à racionalidade típica dos saberes científicos que,
comumente, orienta as práticas pedagógicas na escola. Experimentar e analisar as
diferentes formas de expressão que não se alicerçam apenas nessa racionalidade é
uma das potencialidades desse componente na Educação Básica. Para além da
vivência, a experiência efetiva das práticas corporais oportuniza aos alunos
participar, de forma autônoma, em contextos de lazer e saúde. (BRASIL, 2017, p.
213)

Chama a atenção, no trecho, a valorização de saberes e práticas corporais não oficiais, trazidas do universo cultural dos próprios alunos, conforme está disposto na competência 6 , quanto à valorização da "diversidade de saberes e vivências culturais". (BRASIL, 2017, p. 7)

Das dez competências específicas de Educação Física para o Ensino Fundamental, duas têm relação direta com o tema corpo, as competências 1 e 4:

1. Compreender a origem da cultura corporal de movimento e seus vínculos com a organização da vida coletiva e individual.

[...]

4. Identificar a multiplicidade de padrões de desempenho, saúde, beleza e estética corporal, analisando, criticamente, os modelos disseminados na mídia e discutir posturas consumistas e preconceituosas. (BRASIL, 2017, p. 223). 
Tanto a primeira quanto a quarta competência se relacionam com as implicações do conceito de corpo, considerando experiências individuais e coletivas e aspectos da contemporaneidade, tais como influência da mídia na construção de padrões estéticos e de saúde e em relações de consumo. Percebe-se uma abordagem cultural do corpo, compreendendo-o como dotado de historicidade. Mary Del Priore observa, a respeito do interesse dos historiadores pelo corpo, que

\begin{abstract}
Os corpos são, por natureza, efêmeros. Eis porque a presa do historiador consiste, em grande parte, em representações que são, também, interpretações dadas pela cultura que as produziu. Tais representações encontramos, primeiramente nos textos. Estes dissecam, descrevem, cantam, maltratam os corpos. Ou então, explicam as suas intencionalidades. Outros ainda testemunham uma reflexão mais abstrata sobre o corpo, aplicando-lhe um julgamento estético ou moral, ou precisando sua significação dentro da cultura de um determinado tempo. (DEL PRIORE, 1995, p. 23)
\end{abstract}

Del Priore enfatiza, na relação entre a história e a antropologia, a "busca de lógicas culturais diversas" que atravessam o corpo, levando os historiadores a perceberem como sentidos podiam ser depreendidos de "gestos cotidianos": "O corpo passa, pois, a interessar ao historiador como espaço constitutivo de laços sociais. Seus atos, gestos e práticas são elementos de uma cultura, retratam sistemas de valores específicos, organizam um modo de vida." (DEL PRIORE, 1995, p. 14-15). Atualmente, destaca a historiadora, o corpo aparece avaliado a partir de noções como saúde e sexualidade, tornando-se "medida do mundo":

Os historiadores que se lançaram em outra aventura, aquela de contar-narrarinterpretar a história do corpo, por meio de obras sistêmicas invocam, com insistência, essa articulação com as demandas contemporâneas. "A importância dada ao corpo, no nosso tempo, contrapõe-se ao ofuscamento a que estava submetido no passado [...] os novos valores de beleza, felicidade ou juventude identificaram-se com um corpo que se transforma em objeto de cuidados e desassossegos. 0 projeto de libertação do corpo está presente em cada momento, exprimindo-se numa dinâmica multifacetada e atingindo a imensa teia de relações sociais", explica Jorge Crespo [...] (1990: 7). (DEL PRIORE, 1995, p. 21).

leda Pertuzatti e Ivo Dickmann fazem relações entre os documentos que regem a Educação, a alfabetização e a cultura corporal na Educação Física. O estudo dos pesquisadores percorre a construção legal de documentos e programas educacionais, abordando também a necessidade da reflexão sobre a inserção da Educação Física no campo da linguagem na BNCC e se os seus objetivos e as suas particularidades são contemplados:

A Educação Física está inserida na "Área das Linguagens", principalmente da cultura e das linguagens corporais. Assim, vale destacar que a Educação Física é um componente curricular cuja responsabilidade é tratar das práticas corporais na escola como fenômeno cultural dinâmico, diversificado, pluridimensional, singular e 
contraditório, assegurando aos/às estudantes a construção de um conjunto de conhecimentos necessários à formação plena do cidadão. (DICKMANN; PERTUZATT, 2016, p. 124)

Nesse sentido, destacamos como fundamental a compreensão das competências 2 e 3 da área das Linguagens, que apontam o conhecimento, a utilização e valorização das práticas de linguagens corporais diversas, sem hierarquização de saberes, conforme fica sugerido ainda na competência 5, considerando o campo cultural:

\begin{abstract}
Desenvolver o senso estético para reconhecer, fruir e respeitar as diversas manifestações artísticas e culturais, das locais às mundiais, inclusive aquelas pertencentes ao patrimônio cultural da humanidade, bem como participar de práticas diversificadas, individuais e coletivas, da produção artístico-cultural, com respeito à diversidade de saberes, identidades e culturas. (BRASIL, 2017, p. 61)
\end{abstract}

Em relação às habilidades a serem trabalhadas e desenvolvidas nos anos finais do Ensino Fundamental, momento em que são mais evidentes as transições corporais, destacam-se as seguintes:

(EF89EF08) Discutir as transformações históricas dos padrões de desempenho, saúde e beleza, considerando a forma como são apresentados nos diferentes meios (científico, midiático etc.).

(EF89EF09) Problematizar a prática excessiva de exercícios físicos e o uso de medicamentos para a ampliação do rendimento ou potencialização das transformações corporais. (BRASIL, 2017, p. 237)

Como vemos, a primeira habilidade reforça o que é dito na competência específica 4 do componente curricular Educação Física, alertando para a construção cultural do corpo, incidindo sobre padrões estéticos e de saúde, dados não só por um discurso científico, mas também midiático. No caso da segunda habilitada citada, ela faz referência clara ao desejo do corpo perfeito, projetado por meio da mídia, e ao consumo de itens que colocam em questão a saúde do corpo físico e psicológico, já que podem levar a distorções de imagens e a doenças da mente. Em ambos os casos, acena-se para uma representação social do corpo.

A proposta da BNCC, que se apresenta como um instrumento que visa à melhoria da Educação Básica no país, é questionada por alguns autores. Marcos Neira, por exemplo, afirma que o presente documento "dá vazão a um discurso alinhado com as teorias curriculares tradicionais." (NEIRA, 2018, p. 217). ${ }^{7}$ Em sua análise da BNCC, Neira questiona o primeiro parágrafo do texto introdutório do documento, no qual se lê que este é "de caráter normativo" e

\footnotetext{
${ }^{7}$ As teorias tradicionais do currículo são centradas em tópicas como ensino, aprendizagem, avaliação, didática, organização, eficiência e objetivos, etc. (Cf. SILVA, 2020, p.17). 
que "define o conjunto orgânico e progressivo de aprendizagens essenciais que todos os alunos devem desenvolver ao longo das etapas e modalidades da Educação Básica' (Brasil, 2017, p. 07, grifo do autor)." (NEIRA, 2018, p. 217, negrito do autor). Para 0 autor, a BNCC apresenta um retrocesso político e pedagógico, já que o seu texto se pauta em um discurso neoliberal: "O fato de ter ressuscitado princípios, taxonomias e tipologias da segunda metade do século XX traz à tona a racionalidade técnica revestida pelo discurso neoliberal." (NEIRA, 2018, p. 222)

Seguindo o questionamento sobre o discurso neoliberal, Novaes, Triani e Telles afirmam que "Os direitos de aprendizagem são objetivados e transformados em produtos quantificáveis. Há, nesse sentido, um entendimento de que esses direitos são bens a serem possuídos." (NOVAES, TRIANI; TELLES, 2020, p. 77), transformados, assim, em bens de consumo. Já Cláudia Foganholi questiona a utilização do termo "competências", que, segundo ela, é um reflexo da demanda do universo empresarial, que apoiava e financiava a elaboração deste documento na sua terceira versão. (FOGANHOLI, 2019, p. 7)

Outro autor que questiona a construção dos conteúdos e a organização da BNCC (em seu texto preliminar) é Miguel Arroyo, que faz uma avaliação sobre a forma como a BNCC foi construída: "Os profissionais da Educação Física lembram ao pensamento pedagógico que os educandos e os educadores são totalidades humanas corpóreas. Que os currículos tem de garantir aos educandos os saberes, valores e culturas dos corpos." (ARROYO, 2016, p. 18). Ele evoca questionamentos sobre a leitura da BNCC que dizem respeito a temas como cultura, gênero, condição social, entre outros: "Qual a centralidade dos corpos na Base Nacional Comum? Apontam para outras pedagogias dos corpos?" (ARROYO, 2016, p. 18):

\footnotetext{
Ser profissional da Educação Física exige assumir a identidade educadora da área e dos seus profissionais. Dessa identidade educadora chegam indagações à BNCC, tão centrada em ensinar apenas e tão distante da função Constitucional de formação humana plena. Haverá lugar par a função educadora inerente à Educação Física na estreiteza da BNCC que opta por reduzir o direito à educação apenas ao direito a aprendizagens? (ARROYO, 2016, p. 29)
}

Para Maria do Carmo Martins, a BNCC é pouco ousada no que diz respeito aos direitos sociais e a questões de gênero, que remetem ao corpo e à sexualidade, devido à influência de movimentos como escola sem partido, sendo importante que "a sociedade tenha conhecimento disso, até para que compreenda como esses movimentos influenciam na formulação de políticas públicas, principalmente as vinculadas à educação". (MARTINS apud ALVES FILHO 2017, s/p). A esse respeito, Cilene Pereira observa que houve, de fato, 
[...] um apagamento dessa temática na BNCC, visto que não se textualiza a diversidade sexual e de gênero - muito provavelmente devido ao debate acalorado da questão no cenário nacional, inclusive com tentativas de censura ao tema por meio de projetos que propunham, de modo equivocado, uma "escola sem partido", na qual não fosse tratada a "ideologia de gênero" (outro equívoco terminológico utilizado de má fé por grupos conservadores) e aos interesses de grupos empresarias por detrás da própria aprovação da BNCC [...] (PEREIRA, 2020, p. 191)

A ensaísta lembra, também, que "Recentemente, o Supremo Tribunal Federal (STF) pôs fim à controvérsia [...] ao reconhecer a inconstitucionalidade de leis que proibam a discussão de gênero nas escolas", reafirmando "que a escola é lugar sim de promoção de um debate sobre gênero e diversidade sexual, reconhecendo sua importância e relação direta ao exercício dos DH e à plena cidadania". (PEREIRA, 2020, p. 191-192).

Na perspectiva de Antônio Carlos Amorim, a eleição de currículos mínimos pode fazer que com "disciplinas que trabalham temas considerados mais polêmicos, como questões relacionadas à diversidade de gêneros", percam espaço na sala de aula. (AMORIM apud ALVES FILHO, 2017, s/p). Relacionada a essa questão, estaria também a hierarquização de componentes curriculares, visto que a BNCC "confere ênfase a determinadas disciplinas que considera prioritárias, em detrimento de outras. Um dos interesses em foco são os rankings internacionais que avaliariam a qualidade da educação" (AMORIM apud ALVES FILHO, 2017, $s / p)$.

\section{CONSIDERAÇÕES FINAIS}

0 corpo, independente da fase em que o ser humano se encontra, está inserido em um contexto social e cultural, que interfere no seu entendimento de mundo. Os valores e os conceitos que servem de base para esta ação são permeados de influências locais e históricas. Por isso, "ao pensar nesse corpo em transformação, há de se ter em conta a sua dimensão histórica e cultural. Afinal, qual é a mudança qualitativa (quer seja: cultural e histórica) que constitui a vida dos adolescentes? O que é específico desse momento ontogenético?", questionam Souza e Silva $(2019$, p. 4).

A análise de documentos relativos à Educação Básica, com destaque para os que contemplam o componente curricular Educação Física, revela uma trajetória crítica em relação ao tema do corpo. Nas Diretrizes Curriculares Nacionais e Base Nacional Comum Curricular, vemos que o conceito diversidade se faz bastante presente, estando relacionado a perspectivas culturais diversas, que podem incidir, claro, sobre os corpos. Há, certamente, um avanço no conceito de corpo e no modo como este é entendido no universo escolar e na 
Educação Física, deixando de ser objeto técnico apenas para ser visto em uma dimensão mais plural e diversa.

No caso da BNCC, essa perspectiva é acionada por meio das competências 8, 9 e 10, que, conforme vimos, atravessam temas relativos à Educação Física, apontam para temáticas concernentes à saúde física e emocional do corpo e para como o adolescente percebe seu corpo e constrói sua imagem corporal.

\section{REFERÊNCIAS}

ALVES FILHO, Manuel. Base curricular é conservadora, privatizante e ameaça autonomia, avaliam especialistas. Jornal da Unicamp, Campinas, 4 dez, 2017. Disponível em: https://www.unicamp.br/unicamp/ju/noticias/2017/12/04/base-curricular-e-conservadoraprivatizante-e-ameaca-autonomia-avaliam. Acesso em: 24 de out. 2020.

ARROYO, Miguel G. Corpos resistentes produtores de culturas corporais. Haverá lugar na Base Nacional Comum? Motrivivência, Florianópolis, v. 28, n. 48, p. 15-31, set. 2016. ISSN 21758042. Disponível em: https://periodicos.ufsc.br/index.php/motrivivencia/article/view/21758042.2016v28n48p15. Acesso em: 18 ago. 2020.

BOCK, Ana Mercês Bahia. A adolescência como construção social: estudo sobre livros destinados a pais e educadores. Psicol. Esc. Educ. (Impr.), Campinas, v. 11, n. 1, p. 63-76, Jun 2007. Disponivel em: http://www.scielo.br/scielo.php?script=sci_arttext\&pid=S1413$85572007000100007 \&$ Ing=en\&nrm=iso. Acesso em: 7 ago. 2020.

BRASIL, L. D. B. Lei 9394/96 - Lei de Diretrizes e Bases da Educação Nacional. Disponível em: http://bd.camara.gov.br/bd/bitstream/handle/bdcamara/19339/ldb_13ed.pdf? sequence=46. Acesso em: 27 mar. 2020

BRASIL. Lei no 8.069, de 13 de julho de 1990. Dispõe sobre o Estatuto da Criança e do Adolescente e dá outras providências. Diário Oficial [da] República Federativa do Brasil, Brasília, DF, 16 jul. 1990. Disponível em: https://www.gov.br/mdh/pt-br/centrais-de-conteudo/crianca-eadolescente/estatuto-da-crianca-e-do-adolescente-versao-2019.pdf/@@download/file/estatutoda-crianca-e-do-adolescente-versao-2019.pdf. Acesso em: 25 de mai. 2020.

BRASIL. Ministério da Educação. Base Nacional Comum Curricular. Brasília: MEC, 2017.

BRASIL. Ministério da Educação. Diretrizes Curriculares Nacionais Gerais da Educação Básica. Brasília: MEC, SEB, DICEI, 2013.

BRASIL. Secretaria de Educação Fundamental. Parâmetros curriculares nacionais: introdução aos parâmetros curriculares nacionais. Brasília: MEC/SEF, 1997.

BRASIL. Secretaria de Educação Fundamental. Parâmetros Curriculares Nacionais: Educação física. Brasília: MEC/SEF, 1997. 1. Parâmetros curriculares nacionais. 2. Educação física: Ensino de primeira à quarta série. I. Título. 
BRASIL. Secretaria de Educação Fundamental. Parâmetros Curriculares Nacionais: Educação física. Brasília: MEC/SEF, 1998. 1. Parâmetros curriculares nacionais. 2. Educação Física: Ensino de quinta a oitava séries. I. Título.

CARONI Mariana Malheiros; BASTOS Olga Maria. Adolescência e autonomia: conceitos, definições e desafios. - Revista de Pediatria SOPERJ. v. 15, no 1, p. 29-34, fev. 2015. Disponivel em: http://revistadepediatriasoperj.org.br/detalhe_artigo.asp?id=641. Acesso em: $7 \mathrm{de}$ ago. 2020.

CORREIA, Walter Roberto. Educação Física Escolar: desafiando a sua presumível imutabilidade. Rev. bras. educ. fís. esporte, São Paulo, v. 28, n. 4, p. 691-700, Dec. 2014. Disponível em: http://www.scielo.br/scielo.php?script=sci_arttext\&pid=S1807$55092014000400691 \&$ Ing=en\&nrm=iso. Acesso em: 23 de mai. 2020.

COSTA, Luciane Cristina Arantes da et al. Tecendo relações entre a motivação para as aulas de educação física e o Ideb. Rev. Bras. Ciênc. Esporte, Porto Alegre, v. 40, n. 4, p. 370-373, Dec. 2018. Disponível em: http://www.scielo.br/scielo.php?script=sci_arttext\&pid=S010132892018000400370\&Ing=en\&nrm=iso. Acesso em: 23 de mai. 2020.

DIAS, Diego Corrêa Lima de Aguiar. Direitos Humanos em sala de aula: a compreensão de professores sobre a aliança entre as suas disciplinas escolares e a EDH. Rio de Janeiro: Pontifícia Universidade Católica do Rio de Janeiro, 2017. Disponível em: https://www.maxwell.vrac.puc-rio.br/32243/32243.PDF. Acesso em: 20 de nov. de 2020.

DICKMANN, Ivo; PERTUZATTI, leda. Uma visão panorâmica da LDB à BNCC: as políticas públicas de alfabetização, letramento e suas relações com a cultura corporal na Educação Física. Motrivivência, Florianópolis, v. 28, n. 48, p. 113-129, set. 2016. ISSN 2175-8042. Disponível em: https://periodicos.ufsc.br/index.php/motrivivencia/article/view/21758042.2016v28n48p113. Acesso em: 11 mai. 2020.

FOGANHOLI, Claudia. O contexto da BNCC: reflexões sobre a diversidade na Educação Física Escolar. Temas em Educação Física Escolar, Rio de Janeiro, v. 4, n. 2, p. 5-19, 2019. Disponivel em: http://cp2.gov.br/ojs/index.php/temasemedfisicaescolar/article/viewFile/2474/1645. Acesso em: 28 de out. 2020.

LOURO, Guacira Lopes. Pedagogias da Sexualidade. In: LOURO, Guacira Lopes. (org.) 0 corpo educado: pedagogias da sexualidade. Belo Horizonte: Autêntica, 2000.

MELLO, Guiomar Namo de. Formação inicial de professores para a educação básica: uma (re)visão radical. São Paulo Perspec., São Paulo, v. 14, n. 1, p. 98-110, Mar. 2000. Disponível em: http://www.scielo.br/scielo.php?script=sci_arttext\&pid=S0102$88392000000100012 \&$ Ing=en\&nrm=iso. Acesso em: 19 de mai. 2020.

MELO, Marcia Cristina Henares de; CRUZ, Gilmar de Carvalho. Adolescência e estigma no cotidiano escolar: reflexões à luz de Goffman e Bourdieu. IX ANDEP Sul - 2012. Disponível em: http://www.ucs.br/etc/conferencias/index.php/anpedsul/9anpedsul/paper/viewFile/1089/704. Acesso em: 15 de out. 2020. 
NEIRA, Marcos Garcia. Incoerências e inconsistências da BNCC de Educação Física. Rev.

Bras. Ciênc. Esporte, Porto Alegre, v. 40, n. 3, p. 215-223, 2018. Disponível em:

http://www.scielo.br/scielo.php?script=sci_arttext\&pid=S0101-

32892018000300215\&lng=en\&nrm=iso. Acesso em: 10 de abr. 2020.

NOVAES, Renato Cavalcanti; TRIANI, Felipe da Silva; TELLES, Silvio de Cássio Costa. A Educação Física na Base Nacional Comum Curricular: desconstruindo o discurso neoliberal. Humanidades \& Inovação, v. 7, n. 10, p. 70-84, 2020. Disponível em:

https://revista.unitins.br/index.php/humanidadeseinovacao/article/view/2373. Acesso em: 28 de out. 2020

OLIVEIRA, Marcus Aurélio Taborda de. Educação Física escolar e ditadura militar no Brasil (1968-1984): história e historiografia. Educ. Pesqui., São Paulo, v. 28, n. 1, p. 51-75, June 2002. Disponível em: http://www.scielo.br/scielo.php?script=sci_arttext\&pid=S1517-

97022002000100004\&lng=en\&nrm=iso. Acesso em: 23 mai. 2020.

ORGANIZACIÓN MUNDIAL DE LA SALUD. Problemas de salud de la adolescencia. Geneve: OMS; 1965. (Série de Informes Técnicos, 308). Disponível em:

https://apps.who.int/iris/bitstream/handle/10665/38485/WHO_TRS_308_spa.pdf?sequence=1\&is Allowed=y. Acesso em: 25 mai. 2020.

PEREIRA, Cilene Margarete. Corpo trans e (in)visibilidade no espaço escolar. CRISTOVÃO, Assunção et al. Corpo, tempo e espaço. Franca, 2000. Disponível em:

http://arquivos.cruzeirodosuleducacional.edu.br/criacao/arquivos/unifran/Ebook_Corpo-TempoEspaco.pdf?fbclid=IwAR09PJFLi6Iru3ytAhyUXxcZMzPdqrinJGggQDQloEPDz7irY0OqfwhYzNw. Acesso em 25 de fev. 2021.

PERES, Fumika; ROSENBURG, Cornélio P. Desvelando a concepção de adolescência/adolescente presente no discurso da Saúde Pública. Saúde soc., São Paulo, v. 7, n. 1, p. 53-86, julho, 1998. Disponível em:

http://www.scielo.br/scielo.php?script=sci_arttext\&pid=S0104-

12901998000100004\&Ing=en\&nrm=iso. Acesso em: 3 de ago. 2020.

PREVE, Ana Maria Hoepers; CORREA, Guilherme Carlos. Tudo passa pelo corpo.

Motrivivência, Florianópolis, n. 15, jan. 2000. Disponível em:

https://periodicos.ufsc.br/index.php/motrivivencia/article/view/5593/5355. Acesso em: 7 ago.

2020.

RODRIGUES, Anegleyce Teodoro. Base Nacional Comum Curricular para a área de linguagens e o componente curricular Educação Física. Motrivivência, Florianópolis, v. 28, n. 48, p. 32-41, set. 2016. Disponível em: https://periodicos.ufsc.br/index.php/motrivivencia/article/view/21758042.2016v28n48p32/32560. Acesso em: 18 ago. 2020.

SILVA, Tomaz Tadeu da. Documentos de identidade: uma introdução às teorias do currículo. Belo Horizonte: Autêntica, 2020.

SOUZA, Candida de; SILVA, Daniele Nunes Henrique. Adolescência em debate: contribuições teóricas à luz da perspectiva histórico-cultural. Psicol. Estud., Maringá, v. 23, 2019. Disponível em: http://www.scielo.br/scielo.php?script=sci_arttext\&pid=S1413-

73722018000100228\&lng=en\&nrm=iso. Acesso em: 29 de out. 2020.

Revista de Ciências Humanas, Frederico Westphalen - RS, v. 22, n.2, p. 132-151, maio/ago. 2021. 